\title{
Performance Enhancement of Rectangular Microstrip Antenna with Different Substrate Materials.
}

\author{
Satyanarayana R, Shankaraiah,
}

\begin{abstract}
Above 1GHz, Microstrip antenna is extensively used in Wireless communication. The demand of increased wireless communication applications, needs increase in bandwidth, gain and efficiency of microostrip antenna. Microstrip antenna is a low profile antenna but has narrow bandwidth, low gain and efficiency. In this paper amicrostrip antenna is designed with dimensional change technique to improve bandwidth, gain and efficiency. The enhanced performance of proposed design with different dielectric materials designed and are compared with reference Microstrip antenna. A bandwidth enhancement of $230 \mathrm{MHz}$ and gain enhancement of $8.4 \mathrm{~dB}$ are achieved with proposed antenna.
\end{abstract}

Keywords : Bandwidth, Gain, HFSS, VSWR, Wireless communication

\section{INTRODUCTION}

Communication Engineering Is A Most Rapidly Growing Branch Of Electronics Engineering. Communication Is The Most Basic Need For Progress Of Current Generation Civilization. Antenna Is A Basic Need In Wireless Communication. Above One Ghz Frequency, Wireless Communication, The Microstrip Antenna Is Widely Used.

Microstrip antenna is designed using a dielectric material and two layers of conductors, one on top side and another on bottom side of dielectric material called substrate. The conductive top layer of suitable shape is called patch. The larger area bottom conductive layer is called ground. The different types of patches are rectangular, square, circular and other shapes.[1]

Microstrip antenna has many advantages such as low profile,simple fabrication method, simple to interfacing of ICs.The working of Microstrip antenna can be explained by various methods like Transmission line model and Cavity models[2]. It is used in aircraft, mobile, medical and applications of satellite. The disadvantages of Microstrip Patch Antenna (MPA) are less bandwidth and less gain.

Different research groups are working on these issues. The bandwidth enhancement techniques are DGS, Dimensional change, use of different substrates etc.[3]-[16].

Revised Manuscript Received on December 15, 2019.

* Correspondence Author

Satyanarayana $\mathbf{R}^{*}$, Electronics, JSS Research Foundation S.J.C.E, Mysore University, India, Sathya.sintre@ sjce.ac.in

Dr. Shankaraiah, Professor E \& C Dept, S.J.C.E, Mysore, India, shankaraiah@sjce.ac.in
The gain enhancement of MPA is described here. The gain of MPA can be improved by use of negative permeability metamaterial on low temperature co-fired ceramic (LTCC) substrate is described. WLAN Antenna of 5.2GHz [17] is designed with Split Ring Resonator (SRR) and gain improvement of $1.5 \mathrm{~dB}$ than the conventional antenna is described by authors.

Gain enhancement of MPA using hybrid substrate[18] is described. MPA is designed using substrate with Ferrite ring is described by authors. An antenna with $5-5.6 \mathrm{GHz}$ is designed and an enhancement of $4 \mathrm{~dB}$ gain is achieved by this method. Rectangular microstrip patch antenna Gain and Bandwidth improvement using slot[19] is explained by author. The antenna resonating frequency of $2.5 \mathrm{GHz}$ is designed. The gain improvement of $2 \mathrm{dBi}$ is achieved by loaded slot using IE3D software. A wideband loop and uni-directional antenna by loading of periodic meta-material[20] is explained by author. Gain improvement by loading meta-material in Loop Antenna with directors of arc shape, are tightly coupled. The antenna is designed with frequency of $0.71 .07 \mathrm{GHz}$. A gain of $4.5 \mathrm{dBi}$ is achieved.

A superstate single dielectric AR bandwidth and gain improvement of patch antenna is explained by authors for a 11GHz.A superstate loaded with a single dielectric, a single-feed CP patch antenna for a high gain wide band $\mathrm{cp}$ radiation [21]. In superstate design prototype compared to conventional design an improvement in $3 \mathrm{~dB}$ AR bandwidth of $350 \%$ is obtained. Also a $7 \mathrm{~dB}$ in the broadside gain were obtained. A microstrip antenna gain improvement using superstate of cylindrical Shell [22] shape is explained. A microstrip patch antenna gain enhancement by technique of phase compensation is $3.1 \mathrm{~dB}$. The resonating frequency is 5.5-5.6GHz and simulated using CST microwave studio for gain enhancement of $48 \%$.Gain improvement of MPA with Ferrite Rings[23] is described.Ferrite ring is used to suppress propagation of Electromagnetic waves. This increases the maximum of gain of MPA placed above EBG layer. The maximum gain of $10.9 \mathrm{~dB}$ and Average gain of $9.28 \mathrm{~dB}$ as compared to conventional method maximum gain of $6.37 \mathrm{~dB}$ and average gain of $4.4 \mathrm{~dB}$ in $5.5 \mathrm{GHz}$ to $6 \mathrm{GHz}$ frequency.

Gain enhancement of square microstrip antenna with hybrid substrate[24] is explained. A $5.8 \mathrm{GHz}$ antenna with conventional substrate of Rogers TMM4 gain and hybrid substrate Rogers TMM4 with ferrite ring are compared. An increase of $2.3 \mathrm{dBi}$ in directivity is achieved.

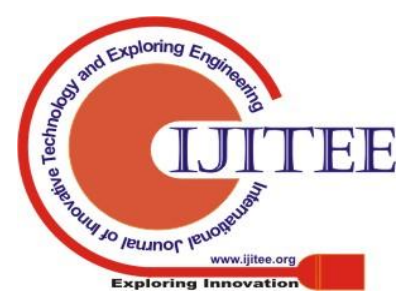


Gain enhancement of square microstrip antenna with $\mathrm{U}$ slot with metallic ring is described in [25]. A $5.8 \mathrm{GHz}$ antenna with $\mathrm{U}$ slot with \& without metal ring are designed and performance in terms of gain are compared. Gain enhancement of $4 \mathrm{~dB}$ is achieved in the frequency range of 5.5 to $6 \mathrm{GHz}$. Gain enhancement of MPA for Wi-Fi applications[26] is described. A gain enhancement of $4.13 \mathrm{dBi}$ is achieved using Mushroom like Electromagnetic band gap EBG structure. A circular patch antenna gain and Bandwidth enhancement with air as dielectric substrate[27] is briefed. The MPA is fed gain and hybrid substrate Rogers TMM4 with ferrite ring are explained.

A circular patch antenna gain and Bandwidth enhancement with air as dielectric substrate[27] is briefed . The MPA is fed from line between two dielectric substrates by an air. The gain improvement $2.39 \mathrm{~dB}$ and bandwidth improvement of $1.35 \%$ more compared to a conventional circular patch antenna using MOM with FEIKO software. Gain enhancement of MPA using modified U slot antenna[28] is described. A dual band 2.45 to $2.47 \mathrm{GHz}$ and 5.1 to $5.4 \mathrm{GHz}$ modified $\mathrm{U}$ slot antenna is designed to achieve peak gain of $6.15 \mathrm{~dB}$ at 2.45 to 2.57 $\mathrm{GHz}$ and $9.1 \mathrm{~dB}$ at $5.27 \mathrm{GHz}$. The Rogers RT / duroid 5880 dielectric substrate is used which cost more than FR-4 material. Gain improvement of MPA using Near zero index metamaterial lens[29] is explained. For WLAN band antenna broadside gain is improved by using metamaterial unit cell as a superstate. The gain improved by $2 \mathrm{dBi}$. MPA Gain enhancement by using multiple layer of substrate[30] is explained. A peak gain improvement of $6.5 \mathrm{dBi}$ is achieved for an antenna of $6.5 \mathrm{GHz}$ resonating frequency. MPA array gain enhancement is described using metallic ring for WLAN / Wi-Fi applications .Rogers Ro 4003 substrate is used. An improvement of $3.1 \mathrm{~dB}$ gain is achieved.

Compared to these methods the proposed method is simple, low cost and gives better results. A rectangular microstrip patch antenna ( RMPA ) is designed with different substrate maaterials. The performance of the RMPA is simulated. The antenna with dimensional change of different substrate materials is designed and simulated using HFSS. The bandwidth and other performance parameters are simulated and compared with that of reference antenna. The organisation of this paper is as given here. Introduction and literature study are described in section I . Section II gives Design, feeding of RMPA and proposed different substrate antenna design. Section III describes modelling and simulation of RMPA and Multiple layer substrate RMPA using HFSS and simulation results. Section IV gives brief comparison of reference RMPA and Enhanced technique of different substrate RMPA and discussion of results. Section V describes conclusion \& future scope. Section VI gives acknowledgements

\section{MATHEMATICAL MODEL DESIGN OF PROPOSED ANTENNA}

Rectangular microstrip patch MPA configuration is most widely used. The mathematical model of RMPA can be explained using models of Transmission Line and Cavity [2].

\section{A. Mathematical Model based on Transmission Line}

Transmission line modelling is most accurate for thin dielectric substrates. Fundamentally Transmission model represents the RMPA by two slots, separated by low impedance $\mathrm{Zc}$ transmission line having length of $\mathrm{L}$. Mathematical model of RMPA using Transmission model is described here. In this analysis the resonating frequency Fr, Substrate dielectric material dielectric constant and dielectric material thickness or height $\mathrm{h}$ of dielectric substrate material are known .The design parameters W - RMPA Width and L Length are calculated.

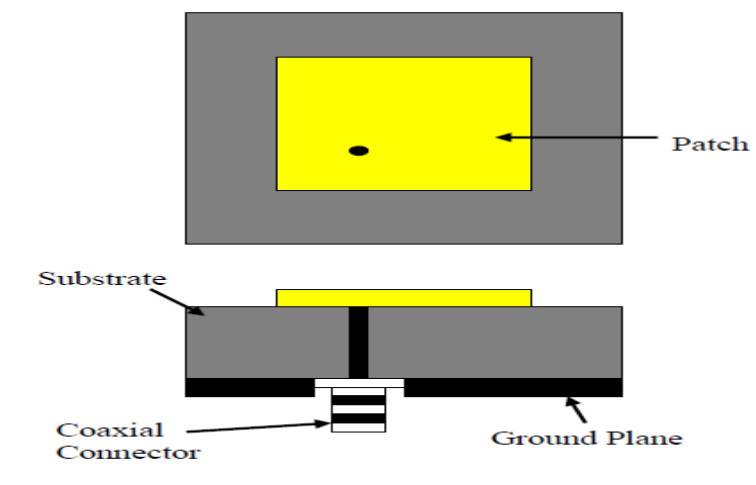

Fig. 1. Probe Feed MPA structure

The RMPA Width $\mathrm{W}$ and Length $\mathrm{L}$ are is calculated as given in by the equations [2],[3]. After calculations, the dimensions of rectangular microstrip patch antenna (RMPA) with different dielectric material are as given in the Table1.

TABLE I

RMSA DIMENSION WITH DIFFERENT DIELECTRIC MATERIALS

\begin{tabular}{|l|l|l|l|l|}
\hline $\begin{array}{l}\text { Sl } \\
\text { No }\end{array}$ & Material & $\begin{array}{l}\text { Width } \\
(\mathrm{mm})\end{array}$ & $\begin{array}{l}\text { Length } \\
(\mathrm{mm})\end{array}$ & $\begin{array}{l}\text { Dielectric } \\
\text { Constant }\end{array}$ \\
\hline 1 & Silicon & 15.85 & 11.38 & 11.9 \\
\hline 2 & Glass & 22 & 16.2 & 5.5 \\
\hline 3 & FR-4 & 22.4 & 16.4 & 4.4 \\
\hline 4 & Hard Rubber & 26.2 & 21.03 & 3.0 \\
\hline 5 & Quartz & 26.6 & 18.8 & 3.78 \\
\hline 6 & Polythene & 29.4 & 24.4 & 2.25 \\
\hline 7 & RT Duroid & 30 & 24.9 & 2.23 \\
\hline
\end{tabular}

\section{B. Feeding techniques :}

There are two types of feedings for MPA as given below.

1) Contact feeding 2) Non-contact feeding.

In contact feeding there are 2 methods. Line feeding and Probe feeding. In Non- contact feeding Aperture feeding and Proximity coupling feeding are well known methods.

The simple feed method is Microstrip Line feed for RMPA, In this line feeding we have 3 types . They are centre feeding,

Offset feeding and inset feeding. This method provides good impedance matching without use of additional matching device. 
The second method is probe feed for RMPA. This method very popular and frequently used for feeding microstrip patch antenna

The third method is Aperture coupled method of feeding RMPA. It is also known as Electro-magnetic coupling. The advantage of Electro-magnetic copuling is low spurious feed radiation, higher reliability, easy matching of impedance.

Proximity coupling technique for RMPA is fourth method. The advantage of Proximity coupled / indirect feed is less spurious feed radiation. The matching of impedance is simple with good reliability. Up to $13 \%$ bandwidth can be obtained. The fabrication is tedious process which also requires alignment.

In proposed RMPA, Probe feed is used.

\section{RESUTLS AND DISCUSSIONS}

Figure 2 shows the modelling and simulation of RMPA using HFSS.

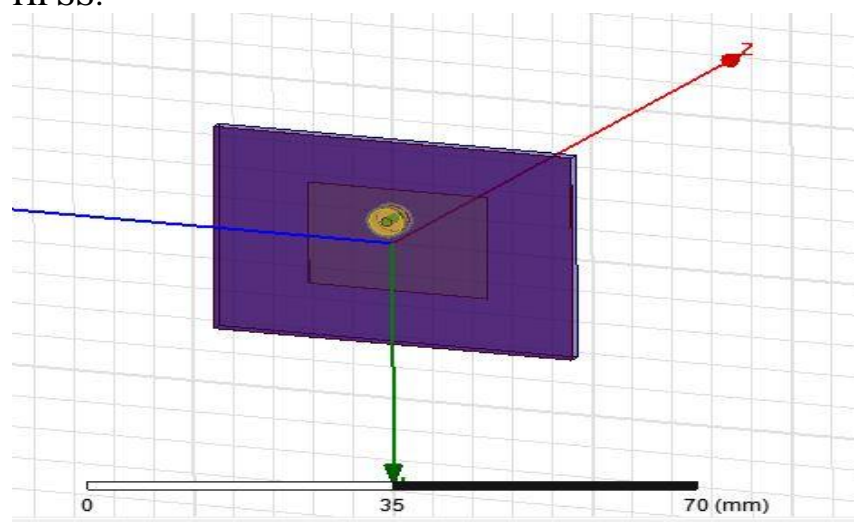

Fig. 2. Proposed MPA Modeling using HFSS

Design of FR-4 microstrip antenna is modeled and simulated by HFSS is shown in figure 2 . This reference antenna has single layer substrate of FR-4 material with thickness of $1.6 \mathrm{~mm}$. This antenna has resonating frequency of $4.08 \mathrm{GHz}$ and bandwidth of $105 \mathrm{MHz}$ and maximum gain of $2.9 \mathrm{~dB}$. To improve gain and also bandwidth another antenna is designed with dimensional change technique.

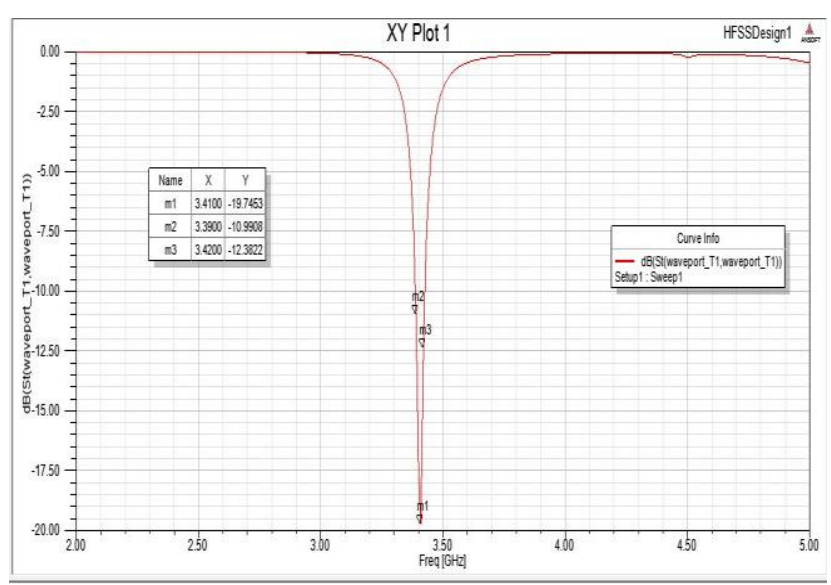

Fig. 3. S11 of Silicon MPA

The S11 characteristics for diffrent substrate materials are shown in Figure 3 to Figure 9. The gain, VSWR and other characteristics are shown in Figure 11 to Figure 18 . From the

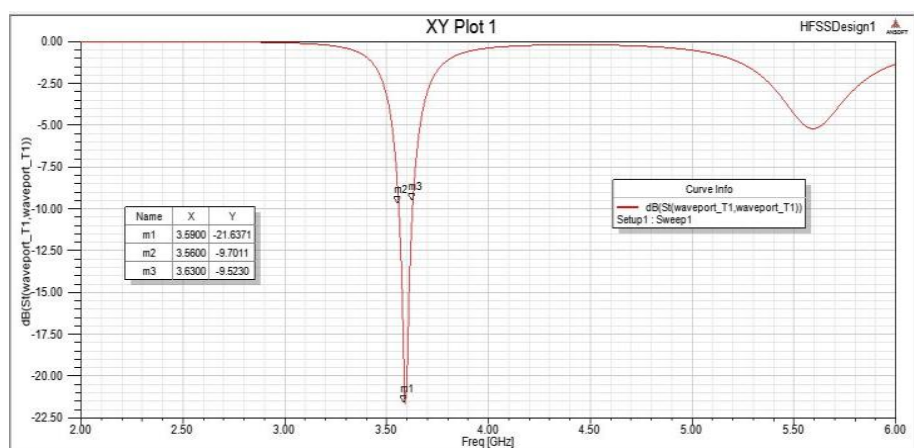

Fig. 4. S11 of Glass MPA

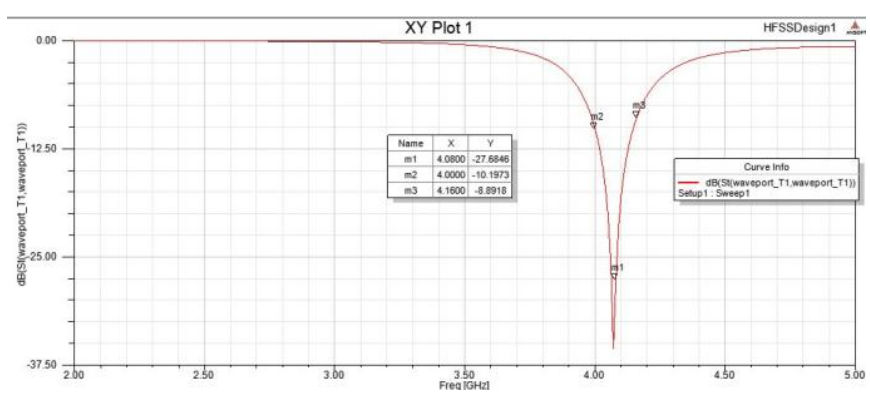

Fig. 5. S11 of Reference MPA

characteristics the value of the maximum S11, gain \& VSWR are given in Table 2 . The $-10 \mathrm{~dB}$ bandwidth are given in Table 3. All these parameters are taken as reference antenna parameters. Since these values are less, so performance enhancement of parameters is achieved by means of proposed dimensional change technique of different substrate material RMPA. The S11 characteristics of Enhanced characteristics different materials substrate is shown in Figure. The Enhanced values are given in Table 4 and Table 5 . From the table we observe there is considerable amount of improvement with proposed technique for different dielectric substrate material.

TABLE II

RESULTS OF ANTENNA PARAMETERS WITH DIFFERENT DIELTRIC SUBSTRATE FOR REFERENCE RMPA

\begin{tabular}{|l|l|l|l|l|}
\hline $\begin{array}{l}\text { Sl } \\
\text { no }\end{array}$ & Material & Frequency & Gain & VSWR \\
\hline 1 & Silicon 2 3 4 5 & $3.4 \mathrm{GHz}$ & $2.13 \mathrm{~dB}$ & 2 \\
\hline 2 & Glass & $3.59 \mathrm{GHz}$ & $3.8 \mathrm{~dB}$ & 1.9 \\
\hline 3 & FR-4 & $4.08 \mathrm{GHz}$ & $2.9 \mathrm{~dB}$ & 1.5 \\
\hline 4 & Hard Rubber & $3.74 \mathrm{GHz}$ & $4.52 \mathrm{~dB}$ & 1.38 \\
\hline 5 & Quartz & $3.7 \mathrm{GHz}$ & $4.5 \mathrm{~dB}$ & 1.1 \\
\hline 6 & Polythene & $3.75 \mathrm{GHz}$ & $5.36 \mathrm{~dB}$ & 1.9 \\
\hline 7 & RT Duroid & $3.4 \mathrm{GHz}$ & $4 \mathrm{~dB}$ & 1.8 \\
\hline
\end{tabular}


Performance Enhancement of Rectangular Microstrip Patch Antenna with Different Substrate Materials

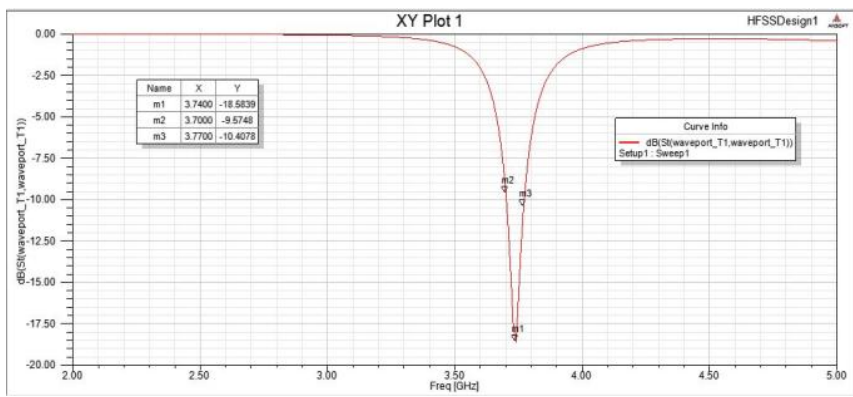

\begin{tabular}{|c|c|c|c|c|}
\hline & & & & \\
\hline 5 & Quartz & $3.74 \mathrm{GHz}$ & $28.55 \mathrm{~dB}$ & $70 \mathrm{MHz}$ \\
\hline 6 & Polythene & $3.75 \mathrm{GHz}$ & $28.6 \mathrm{~dB}$ & $72 \mathrm{MHz}$ \\
\hline 7 & RT Duroid & $3.4 \mathrm{GHz}$ & $23.63 \mathrm{~dB}$ & $100 \mathrm{MHz}$ \\
& & & & \\
\hline
\end{tabular}

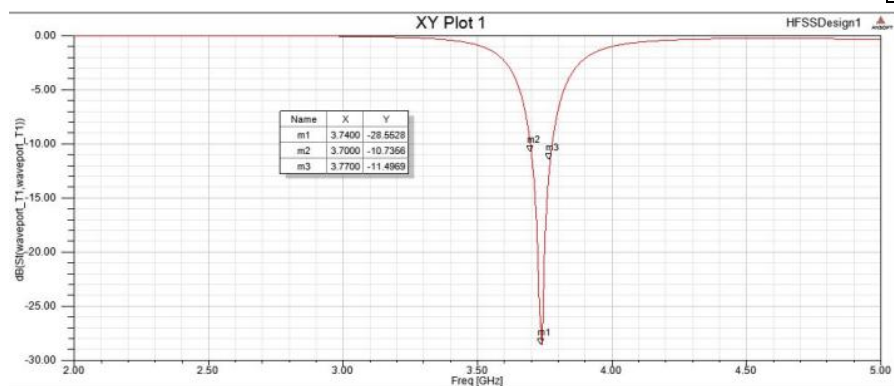

Fig. 7. S11 of Quartz MPA

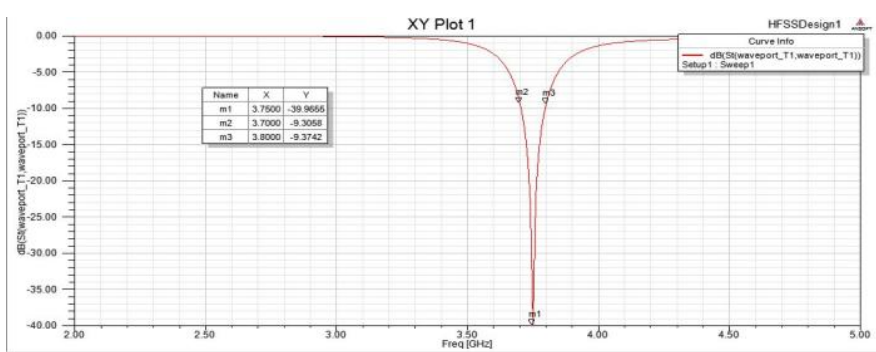

Fig. 8. S11 of Polythene MPA

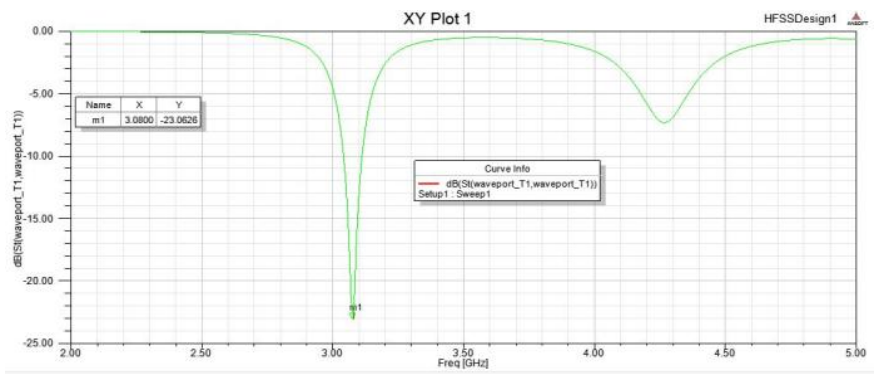

Fig. 9. S11 of RT Duroid MPA

TABLE III

RESULTS OF ANTENNA BANDWIDTH WITH DIFFERENT DIELTRIC SUBSTRATE FOR REFERENCE RMPA

\begin{tabular}{|c|c|c|c|c|}
\hline $\begin{array}{c}\text { S1 } \\
\text { no }\end{array}$ & Material & Frequency & S11 & Bandwidth \\
\hline 1 & Silicon & $3.4 \mathrm{GHz}$ & $19.7 \mathrm{~dB}$ & $30 \mathrm{MHz}$ \\
\hline 2 & Glass & $3.59 \mathrm{GHz}$ & $22 \mathrm{~dB}$ & $70 \mathrm{MHz}$ \\
\hline 3 & FR-4 & $4.08 \mathrm{GHz}$ & $27.68 \mathrm{~dB}$ & $110 \mathrm{MHz}$ \\
\hline 4 & Hard Rubber & $3.7 \mathrm{GHz}$ & $18.58 \mathrm{~dB}$ & $70 \mathrm{MHz}$ \\
\hline
\end{tabular}

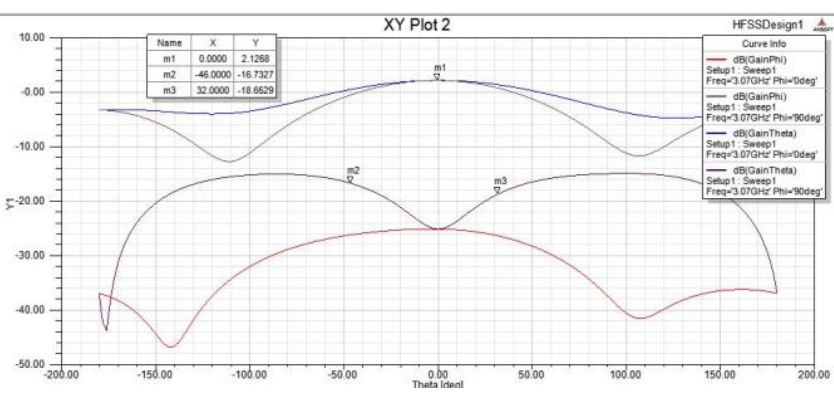

Fig. 10. Gain of Silicon MPA

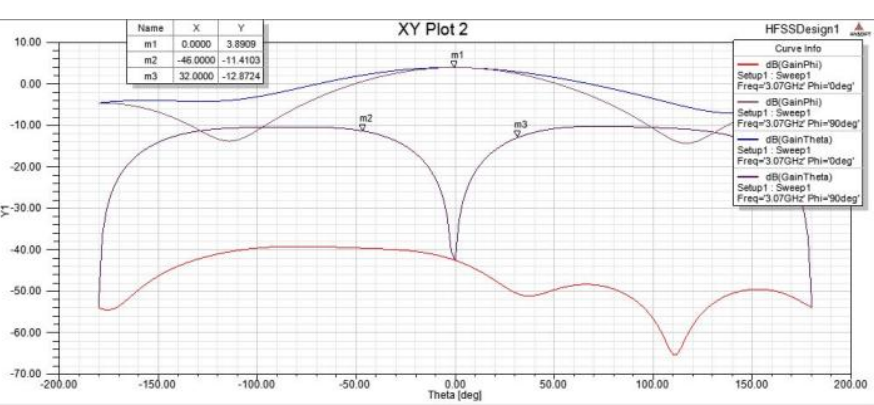

Fig. 11. Gain of Glass MPA

TABLE IV

RESULTS OF ANTENNA PARAMETERS WITH DIFFERENT DIELTRIC SUBSTRATE FOR PROPOSED RMPA

\begin{tabular}{|l|l|l|l|l|}
\hline Sl no & Material & Frequency & Gain & VSWR \\
\hline 1 & Silicon & $3.45 \mathrm{GHz}$ & $\begin{array}{l}3.23 \mathrm{~d} \\
\text { B }\end{array}$ & 1.7 \\
\hline 2 & Glass & $3.63 \mathrm{GHz}$ & $4.8 \mathrm{~dB}$ & 1.7 \\
\hline 3 & FR-4 & $4.1 \mathrm{GHz}$ & $\begin{array}{l}3.95 \mathrm{~d} \\
\text { B }\end{array}$ & 1.2 \\
\hline 4 & Hard Rubber & $3.76 \mathrm{GHz}$ & $\begin{array}{l}5.52 \mathrm{~d} \\
\text { B }\end{array}$ & 1.05 \\
\hline 5 & Quartz & $3.78 \mathrm{GHz}$ & $5.6 \mathrm{~dB}$ & 1.2 \\
\hline 6 & Polythene & $3.75 \mathrm{GHz}$ & $\begin{array}{l}6.36 \mathrm{~d} \\
\text { B }\end{array}$ & 1.6 \\
\hline 7 & RT Duroid & $3.6 \mathrm{GHz}$ & $8.4 \mathrm{~dB}$ & 1.2 \\
\hline
\end{tabular}


TABLE V

RESULTS OF ANTENNA BANDWIDTH WITH DIFFERENT DIELTRIC SUBSTRATE FOR PROPOSED RMPA

\begin{tabular}{|l|l|l|l|l|}
\hline $\begin{array}{l}\text { S1 } \\
\text { no }\end{array}$ & Material & Frequency & S11 & Bandwidth \\
\hline 1 & Silicon & $3.45 \mathrm{GHz}$ & $-21.7 \mathrm{~dB}$ & $75 \mathrm{MHz}$ \\
\hline 2 & Glass & $3.63 \mathrm{GHz}$ & $-23 \mathrm{~dB}$ & $110 \mathrm{MHz}$ \\
\hline 3 & FR-4 & $4.1 \mathrm{GHz}$ & $-31.1 \mathrm{~dB}$ & $230 \mathrm{MHz}$ \\
\hline 4 & Hard Rubber & $3.78 \mathrm{GHz}$ & $-24.71 \mathrm{~dB}$ & $112 \mathrm{MHz}$ \\
\hline 5 & Quartz & $3.76 \mathrm{GHz}$ & $-30.5 \mathrm{~dB}$ & $107 \mathrm{MHz}$ \\
\hline 6 & Polythene & $3.75 \mathrm{GHz}$ & $-26.55 \mathrm{~dB}$ & $110 \mathrm{MHz}$ \\
\hline 7 & RT Duroid & $3.4 \mathrm{GHz}$ & $-29.72 \mathrm{~dB}$ & $205 \mathrm{MHz}$ \\
\hline
\end{tabular}

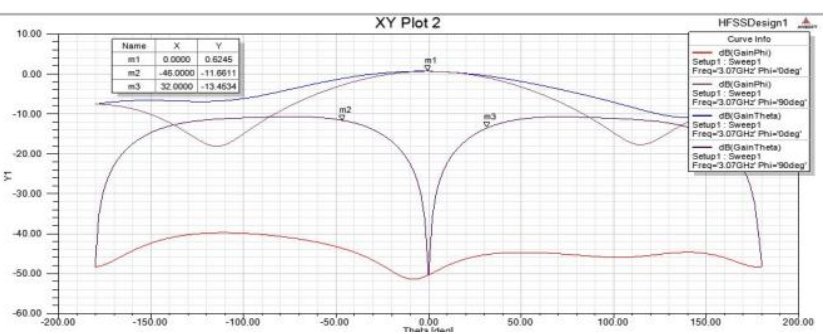

Fig. 12. Gain of FR-4 MPA

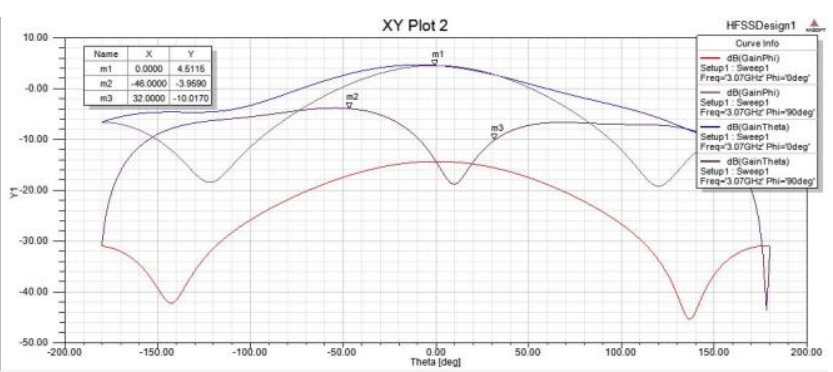

Fig. 13. Gain of Hard Rubber MPA

\section{PERFORMANCE COMPARISON OF REFRENCE AND PROPOSED ANTENNA}

The comparison of different dielectric substrate materials reference and proposed RMPA, are given in Table No. 5 to 11 .

TABLE VI

PERFORMANCE COMPARISON OF SILICON REFERENCE AND PROPOSED RMPA

\begin{tabular}{|l|l|l|l|}
\hline $\begin{array}{l}\text { Sl } \\
\text { no }\end{array}$ & Parameter & $\begin{array}{l}\text { Reference } \\
\text { RMPA }\end{array}$ & $\begin{array}{l}\text { Proposed } \\
\text { RMPA }\end{array}$ \\
\hline 1 & Resonance Frequency & $3.4 \mathrm{GHz}$ & $3.45 \mathrm{GHz}$ \\
\hline 2 & S11 & $-19.7 \mathrm{~dB}$ & $-21.7 \mathrm{~dB}$ \\
\hline 3 & Bandwidth & $30 \mathrm{MHz}$ & $75 \mathrm{MHz}$ \\
\hline 4 & Gain & $2.13 \mathrm{~dB}$ & $3.2 \mathrm{~dB}$ \\
\hline 5 & Input impedance & 50 ohms & 50 Ohms \\
\hline 6 & Radiation pattern & Hemisphere & Hemisphere \\
\hline 7 & VSWR & 2.0 & 1.7 \\
\hline
\end{tabular}

TABLE VIII

PERFORMANCE COMPARISON OF FR-4 REFERENCE AND PROPOSED RMPA

\begin{tabular}{|c|c|c|c|}
\hline $\begin{array}{l}\text { Sl } \\
\text { no }\end{array}$ & Parameter & $\begin{array}{l}\text { Reference } \\
\text { RMPA }\end{array}$ & $\begin{array}{l}\text { Proposed } \\
\text { RMPA }\end{array}$ \\
\hline 1 & Resonance Frequency & $4.08 \mathrm{GHz}$ & $4.1 \mathrm{GHz}$ \\
\hline 2 & S11 & $-27.7 \mathrm{~dB}$ & $-31.1 \mathrm{~dB}$ \\
\hline 3 & Bandwidth & $110 \mathrm{MHz}$ & $230 \mathrm{MHz}$ \\
\hline 4 & Gain & $2.9 \mathrm{~dB}$ & $3.95 \mathrm{~dB}$ \\
\hline 5 & Input impedance & 50 ohms & 50 Ohms \\
\hline 6 & Radiation pattern & Hemisphere & Hemisphere \\
\hline 7. & Patch Resistance & 218 ohms & 217 ohms \\
\hline 7 & VSWR & 1.5 & 1.2 \\
\hline
\end{tabular}


The comparison of FR-4 reference and proposed RMPA with multiple substrate, multilayer are shown in Table No. 7.

From comparison, it is found resonance frequency is more in proposed RMPA and bandwidth is also more. The bandwidth is enhanced by $104.5 \%$ The gain is enhanced from 2.9 to $3.95 \mathrm{~dB}$. There is $36.2 \%$ enhancement in gain. The directivity and Radiation pattern are comparable with improvement of $1 \mathrm{~dB}$. The total resistance of patch and input resistance are also comparable. The VSWR of reference RMPA is around 1.5 and is acceptable. The VSWR of Proposed RMPA is 1.1 is and it is perfect matching of antenna with transmission line. From comparison the bandwidth and gain is enhanced by $104.5 \%$ and $36.26 \%$ in proposed antenna and has better performance enhancement.

TABLE IX

PERFORMANCE COMPARISON OF HARD RUBBER REFERENCE AND PROPOSED RMPA

\begin{tabular}{|l|l|l|l|}
\hline $\begin{array}{l}\text { Sl } \\
\text { no }\end{array}$ & Parameter & $\begin{array}{l}\text { Reference } \\
\text { RMPA }\end{array}$ & $\begin{array}{l}\text { Proposed } \\
\text { RMPA }\end{array}$ \\
\hline 1 & Resonance Frequency & $3.74 \mathrm{GHz}$ & $3.78 \mathrm{GHz}$ \\
\hline 2 & S11 & $-18.58 \mathrm{~dB}$ & $-24.7 \mathrm{~dB}$ \\
\hline 3 & Bandwidth & $70 \mathrm{MHz}$ & $110 \mathrm{MHz}$ \\
\hline 4 & Gain & $4.5 \mathrm{~dB}$ & $5.52 \mathrm{~dB}$ \\
\hline 5 & Input impedance & 50 ohms & 50 Ohms \\
\hline 6 & Radiation pattern & Hemisphere & Hemisphere \\
\hline 7 & VSWR & 1.5 & 1.1 \\
\hline
\end{tabular}

The comparison of Hard Rubber reference and proposed RMPA are shown in Table No. 9. From comparison, it is found resonance frequency is more in proposed RMPA and bandwidth is also more. The bandwidth is enhanced by $57.15 \%$ The gain is enhanced from 4.5 to $5.52 \mathrm{~dB}$. There is $22.7 \%$ enhancement in gain. The directivity and Radiation pattern are comparable with improvement of $1 \mathrm{~dB}$. The total resistance of patch and input resistance are also comparable. The VSWR of reference RMPA is around 1.5 and is acceptable. The VSWR of Proposed RMPA is 1.1 is and it is perfect matching of antenna with transmission line. From comparison the bandwidth and gain are enhanced by $57.15 \%$ and $22.7 \%$ in proposed antenna and has better performance enhancement.

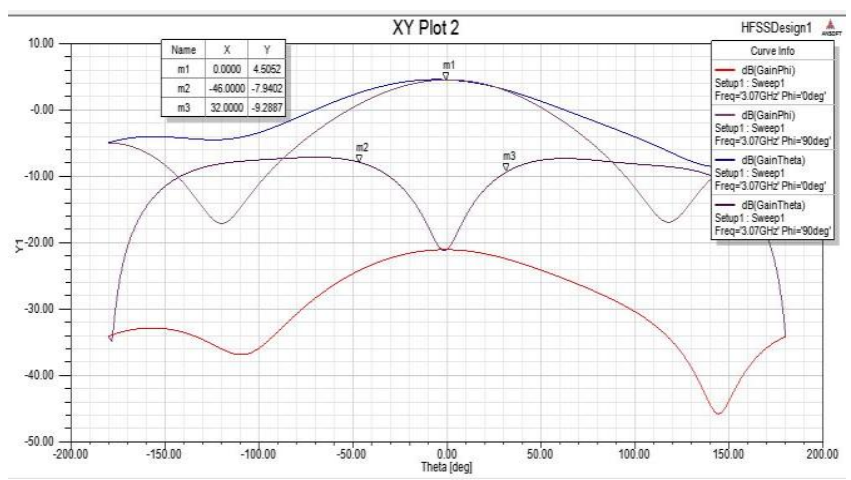

Fig. 14. Gain of Quartz MPA

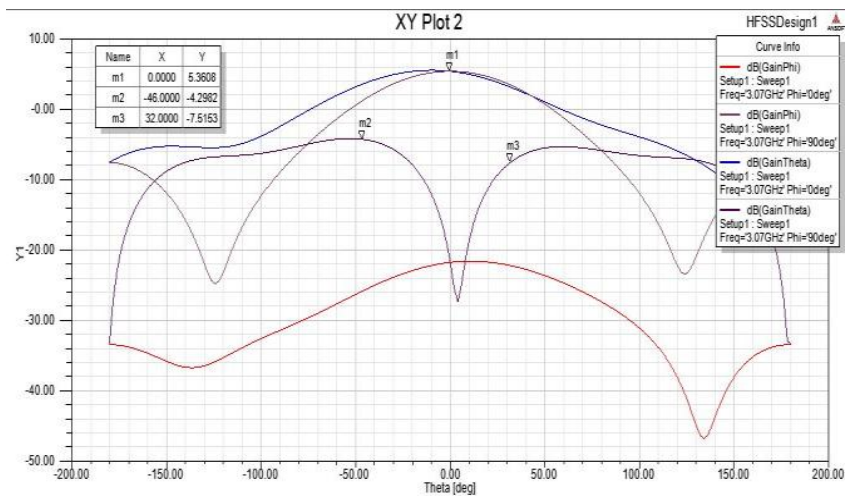

Fig. 15. Gain of Polythene MPA

\section{TABLE X \\ PERFORMANCE COMPARISON OF QUARTZ REFERENCE AND PROPOSED RMPA}

\begin{tabular}{|l|l|l|l|}
\hline $\begin{array}{l}\text { Sl } \\
\text { no }\end{array}$ & Parameter & $\begin{array}{l}\text { Reference } \\
\text { RMPA }\end{array}$ & $\begin{array}{l}\text { Proposed } \\
\text { RMPA }\end{array}$ \\
\hline 1 & Resonance Frequency & $3.76 \mathrm{GHz}$ & $3.74 \mathrm{GHz}$ \\
\hline 2 & S11 & $-28.55 \mathrm{~dB}$ & $-30.5 \mathrm{~dB}$ \\
\hline 3 & Bandwidth & $70 \mathrm{MHz}$ & $107 \mathrm{MHz}$ \\
\hline 4 & Gain & $4.5 \mathrm{~dB}$ & $5.6 \mathrm{~dB}$ \\
\hline 5 & Input impedance & 50 ohms & 50 Ohms \\
\hline 6 & Radiation pattern & Hemisphere & Hemisphere \\
\hline 7. & Patch Resistance & 218 ohms & 217 ohms \\
\hline 7 & VSWR & 1.1 & 1.05 \\
\hline
\end{tabular}

The comparison of Quartz reference and proposed RMPA with multiple substrate, multilayer are shown in Table No. 10 From comparison, it is found resonance frequency is more in proposed RMPA and bandwidth is also more. The bandwidth is enhanced by $67.14 \%$ The gain is enhanced from 4.5 to $5.6 \mathrm{~dB}$. There is $24.4 \%$ enhancement in gain. The directivity and Radiation pattern are comparable with improvement of $1 \mathrm{~dB}$. The total resistance of patch and input resistance are also comparable. The VSWR of reference RMPA is around 1.5 and is acceptable. The VSWR of Proposed RMPA is 1.05 is and it is perfect matching of antenna with transmission line. From comparison the bandwidth and gain are enhanced by $67.14 \%$ and $22.4 \%$ in proposed antenna and has better performance enhancement.

TABLE XI

PERFORMANCE COMPARISON OF POLYTHENE REFERENCE AND PROPOSED RMPA

\begin{tabular}{|l|l|l|l|}
\hline $\begin{array}{l}\text { S1 } \\
\text { no }\end{array}$ & Parameter & $\begin{array}{l}\text { Reference } \\
\text { RMPA }\end{array}$ & $\begin{array}{l}\text { Proposed } \\
\text { RMPA }\end{array}$ \\
\hline 1 & Resonance Frequency & $3.75 \mathrm{GHz}$ & $3.75 \mathrm{GHz}$ \\
\hline 2 & S11 & $-28.6 \mathrm{~dB}$ & $-26.5 \mathrm{~dB}$ \\
\hline 3 & Bandwidth & $70 \mathrm{MHz}$ & $112 \mathrm{MHz}$ \\
\hline 4 & Gain & $5.36 \mathrm{~dB}$ & $6.4 \mathrm{~dB}$ \\
\hline 5 & Input impedance & 50 ohms & 50 Ohms \\
\hline 6 & Radiation pattern & Hemisphere & Hemisphere \\
\hline 7 & VSWR & 1.5 & 1.2 \\
\hline
\end{tabular}


The comparison of Polythene reference and proposed RMPA are shown in Table No. 11. From comparison, it is found resonance frequency proposed RMPA and bandwidth is same. The bandwidth is enhanced by $74.3 \%$ The gain is enhanced from 5.36 to $6.4 \mathrm{~dB}$. There is $19.4 \%$ enhancement in gain. The directivity and Radiation pattern are comparable with improvement of $1 \mathrm{~dB}$. The total resistance of patch and input resistance are also comparable. The VSWR of reference RMPA is around 1.9 and is acceptable. The VSWR of Proposed RMPA is 1.2 is and it is very good matching of antenna with transmission line. From comparison the bandwidth and gain are enhanced by $74.3 \%, 19.4 \%$ in proposed antenna and has better performance enhancement

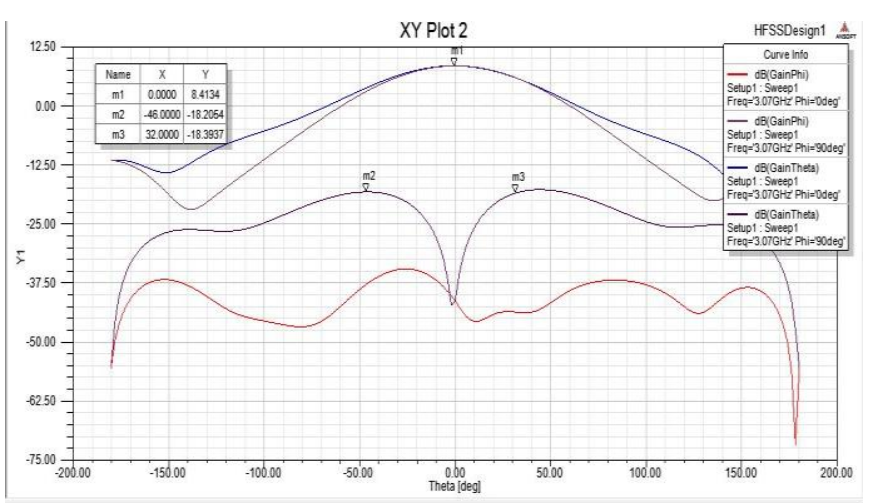

Fig. 16. Gain of RT Duroid MPA

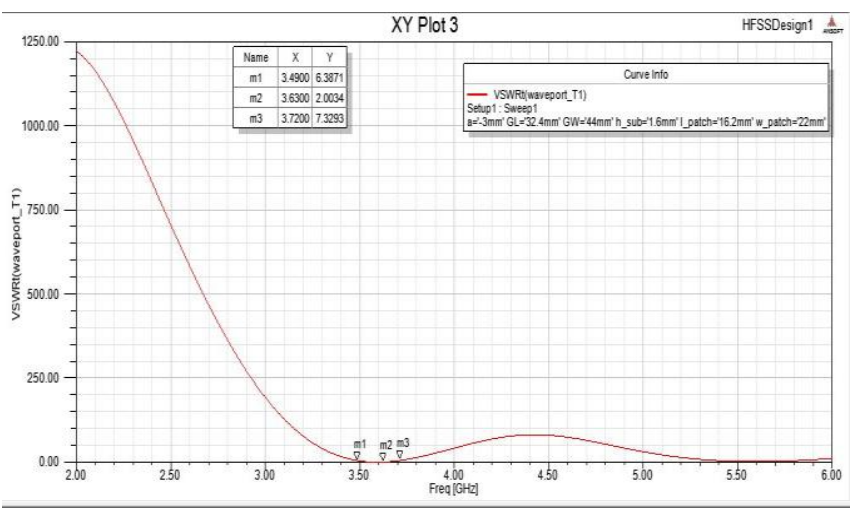

Fig. 17. VSWR of Glass MPA

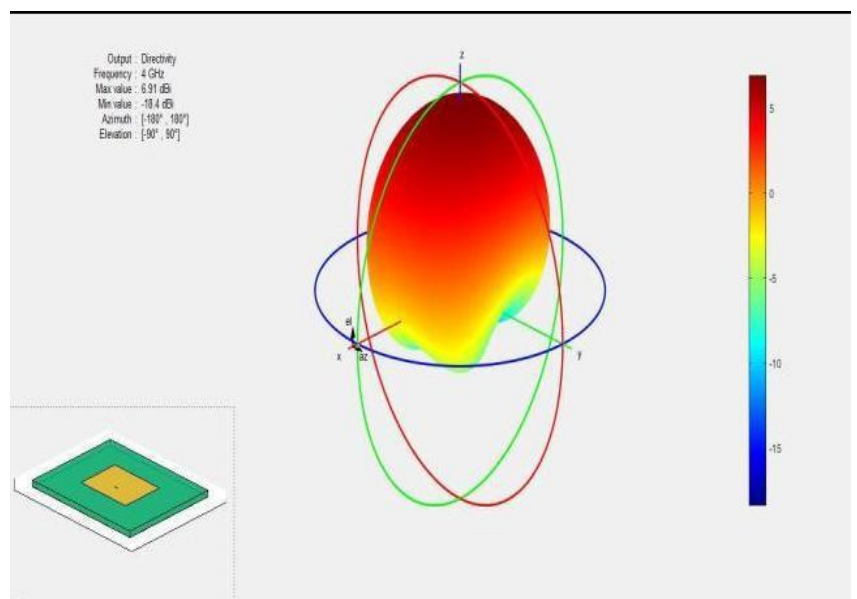

Fig. 18. Matlab simulation of Reference MPA
TABLE XII

PERFORMANCE COMPARISON OF RT DUROID REFERENCE AND PROPOSED RMPA

\begin{tabular}{|l|l|l|l|}
\hline $\begin{array}{l}\text { Sl } \\
\text { no }\end{array}$ & Parameter & $\begin{array}{l}\text { Reference } \\
\text { RMPA }\end{array}$ & $\begin{array}{l}\text { Proposed } \\
\text { RMPA }\end{array}$ \\
\hline 1 & Resonance Frequency & $3.4 \mathrm{GHz}$ & $3.6 \mathrm{GHz}$ \\
\hline 2 & S11 & $-23.6 \mathrm{~dB}$ & $-29.7 \mathrm{~dB}$ \\
\hline 3 & Bandwidth & $100 \mathrm{MHz}$ & $205 \mathrm{MHz}$ \\
\hline 4 & Gain & $4.6 \mathrm{~dB}$ & $8.4 \mathrm{~dB}$ \\
\hline 5 & Input impedance & 50 ohms & 50 Ohms \\
\hline 6 & Radiation pattern & Hemisphere & Hemisphere \\
\hline 7 & VSWR & 1.5 & 1.1 \\
\hline
\end{tabular}

. The comparison of RT- Duroid and proposed RMPA are shown in Table No. 12. From comparison, it is found resonance frequency same in proposed RMPA and bandwidth is more. The bandwidth is enhanced by $105 \%$ The gain is enhanced from 4.6 to $8.4 \mathrm{~dB}$. There is $82.61 \%$ enhancement in gain. The directivity and Radiation pattern are comparable with improvement of $1.3 \mathrm{~dB}$. The total resistance of patch and input resistance are also comparable. The VSWR of reference RMPA is around 1.5 and is acceptable.The VSWR of Proposed RMPA is 1.1 is and it is perfect matching of antenna with transmission line. From comparison the bandwidth and gain are enhanced by $105 \%$ and $82.6 \%$ in proposed antenna and has better performance enhancement

\section{CONCLUSION AND FUTURE WORK.}

Rectangular microstrip patch antenna(RMPA) is designed with $1.6 \mathrm{~mm}$ of different substrates and with dimensional change techniques. The performances are compared. Bandwidth, gain and other parameters different dielectric materials of reference. antenna and proposed antenna are compared. Bandwidth of Silicon reference lowest value of 30 $\mathrm{MHz}$, but \% enhancement is max and is $150 \%$. The Max. value of Bandwidth is found in FR-4 material, then in RT-Duroid material. The gain value enhancement is maximum with RT duroid and lowest with Polytene material. When more bandwidth moderate gain are required FR-4 di-electric is preferred and both moderate bandwidth and high gain required RT duroid is preferred. Hence there is a bandwidth and gain enhancement of with proposed antenna. There is also improvement in directivity and VSWR performance. Hence proposed antenna performance of is enhanced, without affecting performance of other parameters. The Future work RMPA performance enhancement can be extended for various shapes of microstrip patch with other types of feed methods and different shapes of slots.

\section{ACKNOWLEDGMENT}

We thank University of Mysore, JSS Research Foundation and S.J.C.E Mysore for encouragement and support.

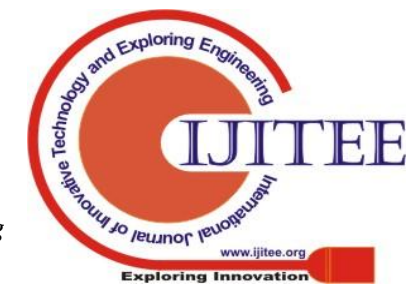




\section{REFERENCES}

[1] R. Kiruthika and Dr. T. Shanmuganatham Comparison of different shapes in microstrip patch antenna for X- band applications. IEEE 978-1-5090-

$3751-3 / 162016$

[2] C. A. Balanis, Antenna Theory Analysis and Design, John Wiley and Sons. Inc. October 2003

[3] R.Satyanarayana and Dr. Shankaraiah "Performance Enhancement of Probe Fed Microstrip Patch Antenna for Wireless Communication Application",IEEE 978-1-5386-2361-9/17/ Dec. 2017

[4] Halappa R. Gajera Edge Truncated square microstrip Patch Antenna [ETCSMPA] for wireless application. IEEE 978-1-4577-1457-3/11, 2011

[5] Sudhanshu verma and Preetham Kumar Printed Egg curved slot Antenna for Wideband Application. Progress in Electromagnetics B , Vol. 58, 111-1212014

[6] Gullu Kiziltas , Pschoudokis and Norboru kikruchi Topology Design optimization of Dielectric substrates for Bandwidth improvement of a patch Antenna. IEEE Trans. On Antennas and Propagation Vol. 51 , No 10 , October 2003

[7] Hassein Mosallaei and Kamal sarabandi , Antenna Miniaturization and Bandwidth Enhancement using a Reactive impedance substrate. IEEE Trans. On Antennas and Propagation Vol. 52, No 09 September 2004

[8] Y. Sung. Bandwidth Enhancement of Microstrip Line fed printed wide slot Antenna with parasitic centre patch IEEE Trans. On Antennas and Propagation Vol. 60, No 4 April 2012

[9] Semyoung oh, Member IEEE, Hanjun Lee and Mingoo Shin Miniaturization of Microstrip Antenna by using Transformation Electromagnetics IEEE Antennas and Wireless propagation Letters, Vol. 15, 2016

[10] Kin Lu Wong Tusung Ju ww \& Po-wel Lin, Small size Uniplannar WWAV Tablet Computer Antenna using parallel resonant strip for Bandwidth

Enhancement IEEE Transaction Antenna and Propagation, Vol.61, No 1, Jan 2013

[11] Marhrukh Khan student member IEEE and Chatterjeee Member IEEE Characteristics Mode analysis of a class of Empirical design techniques

for probe-fed ,U slot microstrip antenna. IEEE Transaction on Antennas \& propagation ,Vol . XX, No X , 2015

[12] Homoyar Oraizi Roza pazads Radiation Bandwidth Enhancement of Aperture Stacked Microstrip Antennas IEEE Transactions on Antennas and Propagation., Vol. 60 , No 4, April 2012

[13] Hong-Yin Zhang,Fu-Shun Zhang, Fan Zhang,Tian Li and Chao Li Bandwidth Enhancement of a Horizontally polarized omnidirectional Antenna by adding parasitic Strip IEEE Antennas \& Propagation Letters, Vol. 16, 2017

[14] Jin-Dong Zhang, Lei Zhu, Qiong Sen Wu, Neng Wu Liu,and Wen Wu A compact microstrip-fed patch antenna with Enhanced Bandwidth and Harmonic suppression. IEEE Transactions on Antennas \& Propagation , Vol. 64, No 12, December 2016

[15] Mikal Askarian Amiri, C.A Balanias and Craig R Birther Gain and Bandwidth Enhancement of a Spiral Antenna using circularly symmetric HIS. IEEE Antennas \& Wireless propagation Letters . Vol. 16,2017

[16] Kuan-Wei Li, Wen-Bin Tsai and Chien-Jang Waung Enhancement of impedance Bandwidth for the Microstrip Monopole Slot Antenna.Progress in Electromagnetic Research Symposium ( PIERS) Shangai China 8-11 Aug 2016

[17] Zhenzhe Liu, Peng Wang, and Zhiyi Zeng Enhancement of the Gain for Microstrip Antennas Using Negative Permeability Metamaterial on Low temperature Co-Fired Ceramic (LTCC) Substrate IEEE Antennas and Wireless propagation Letters Vol. 12, 2013

[18] Alix Rivera-Albino, Member, IEEE, and Constantine A. Balanis, Life Fellow, IEEE Gain Enhancement in Microstrip Patch Antennas using Hybrid Substrates IEEE Antennas and Wireless propagation Letters Vol.12, 2013

[19] Ravi Kant Prasad, D.K.Srivastava and J.P.Saini Gain and Bandwidth Enhancement of Rectangular Microstrip Antenna by Loading Slot 2016

1st International Conference on Innovation and Challenges in Cyber Security (ICICCS 2016)

[20] S. Ahdi Rezaeieh,M. A. Antoniades, and A. M. Abbosh, Gain Enhancement of Wideband Metamaterial-Loaded Loop Antenna With Tightly Coupled Arc-Shaped Directors IEEE Tranactions on Antennas and Propagation, Vol. 65, No. 4, April 2017

[21] S.X. Ta and T.K. Nguyen AR bandwidth and gain enhancements of patch antenna using single dielectric superstrate, IEEE Electronic Letters,Vol. 53 No. 15 pp. 10151017 , July 2017
[22] Masoud Sharifian Mazraeh Mollaei, Esmaeel Zanganeh, and Masoud Feshki Farahan Enhancement of Patch Antenna Gain Using Cylindrical Shell-Shaped Superstratei IEEE Antennas and Wireless Propagation Letters, Vol. 16, 2017

[23] Alix Rivera-Albino and Constantine A Balanis Gain Enhancement in Microstrip Patch Antennas Using Ferrite Rings IEEE 978-1-4799-1129-5/13/ 2013

[24] Arvind Kumar Mithilesh Kumar,Gain Enhancement in A Novel Square Microstrip Patch Antenna Using Hybrid Substrates, IEEE 978-1-4799-2866-8/14 2014 IEEE

[25] Arvind Kumar, Mithilesh Kumar Gain Enhancement in A Novel Square Microstrip Patch Antenna Using Metallic Rings , IEEE 978-1-4799-4040-0114/20 14

[26] Neeraj Rao, Dr. Dinesh Kumar V Gain Enhancement of Microstrip Patch Antenna for Wi-Fi Applications, IEEE 978-1-4799-3662-5/14 2014

[27] TVS Divakar, Dhruba C. Panda Gain and Bandwidth Enhancement of a Circular Microstrip Patch Antenna with an Air Dielectric between Two

Substrates, IEEE 978-1-4799-3267-2/13/1.00 013

[28] Swaraj Panusa, Mithilesh Kumar Modified U-Slot Microstrip Patch Antenna with Gain Enhancement, IEEE 978-1-4799-6929-6/14 2014

[29] Hemant Suthar, Debdeep Sarkar, Kushmanda Gaurav, Kumar Vaibhav Srivastava Gain Enhancement of Microstrip Patch Antenna using Near zero Index Metamaterial (NZIM) Lens, IEEE 978-1-4799-6619-6/15,2015

[30] Collins Nduka Ineneji, Mehmet Kusaf Gain Enhancement In Microstrip Patch Antenna Using The Multiple Substrate Layer Method, IEEE 978-1-4799- 4874-1/14/2015

\section{AUTHORS PROFILE}

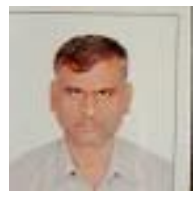

Satyanarayana.R received B.E degree in Electrical and Electronics Engineering from Mysore University, Karnataka,India in 1997. He Received M.Tech in VLSI Design \& Embedded systems from Visvesraya Technological University in 2012. Currently he is Research Scholar of Electronics in SJCE, JSS Research Foundation under Mysore University. He has more than 15 years industrial experience and more than 7 years teaching and research experience. His area of interests are Embedded System Product Design, Testing and Software Testing, Analog VLSI Design and implementation, Microstrip Antennas, EMI / EMC Design \& Testing.

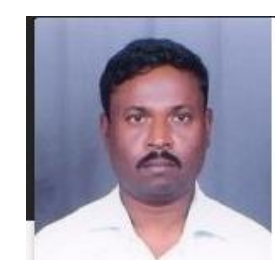

Dr. Shankaraiah received his B.E degree in Electronics and Communication Engineering from Mysore university in 1994. M.Tech Degree in Digital Communication systems from Mysore university 1997. He completed his Ph.D under the guidance of Prof.P.Venkataraman Dept. of ECE,IISC Bangalore. He has investigated a transaction based on QoS,Resource Managemen scheme for mobile communication. He has more than 20 years of teaching experience in Engineering. He published more than 30 papers in national and international journals and conferences. He is reviewer and Chair for many conferences. His research includes Bandwidth Management, Quality of service ( QoS) management, topology management and Energy Management for Hybrid wireless superstore environments. He is a Life member for India society for Technical Education (LMISTE). Presently working as Professor and Head in the department of E \& C of Sri Jayachamarajendra College of Engineering, Mysore, Karnataka India 